\title{
Experimental investigation on acclimatized wastewater for membrane bioreactors
}

\author{
W. S. Guo, S. Vigneswaran*, H. H. Ngo, W. Xing \\ Faculty of Engineering, University of Technology, Sydney, \\ PO Box 123, Broadway, NSW 2007, Australia \\ Tel: +61 (2) 95142641, Fax: + 61(2) 95142633, Email: s.vigneswaran@uts.edu.au
}

\begin{abstract}
The inoculation and acclimatization of activated sludge (AS) is one of the vital components to provide preferably suspended aerobic growth and desired treatment mechanism for a treated wastewater using MBR. The performance of a floating media biofilter-submerged membrane bioreactor (FMB-SMBR) and a submerged membrane adsorption bioreactor (SMABR) were investigated during the acclimatization. It was observed that the duration of sludge from wastewater treatment plant in Sydney acclimated to synthetic wastewater was about 25 days for FMB-SMBR system, while SMABR took around 12 days to reach the stabilization. The acclimatized FMBSMBR (without membrane operation) resulted in significant high dissolved organic removal of $94 \%$. The acclimatized FMBR-SMBR system showed more than $20 \%$ TOC removal efficiency than that of the acclimatized SMABR system. Meanwhile, the results of oxygen uptake rate (OUR) measurement suggested that OUR is an accurate and simple indicator to biological process acclimatization. Membrane fouling study of the FMB-CFMF system was also carried out. The results indicate that the acclimatized FMB could be used as a pretreatment unit prior to SMBR in order to minimize membrane fouling when the FMB-SMBR system operates under subcritical flux condition.
\end{abstract}

Keywords: Oxygen uptake rate; Membrane bioreactor acclimatization; Floating media biofilter

\section{Introduction}

The consumption of limited waste resources in combination with more stringent water quality regulations, and the need for reuse of water have been the main driving forces for the development of membrane technologies. Among the membrane processes, membrane bioreactor (MBR) technologies are becoming an innovative and promising option for wastewater treatment and reuse. MBR associates a suspended growth bioreactor and a filtration on porous membrane, which leads to the total retention of biomass (high microbial concentration) and improved biological reactor operation (high sludge ages) in the bioreactor [1].

* Corresponding author 
Although MBRs offer the effective separation of pollutants and persistence to high or shock loadings, membrane fouling is still an unavoidable obstacle. The characteristics of activated sludge (AS) in MBR are one of the cardinal factors to membrane fouling. The sludge matrix within MBR is mixed liquor of two main fractions: (i) biological flocs formed by a large range of living microorganisms, and (ii) supernatant containing soluble and colloidal compounds. Each element has its own physicochemical and biological properties affecting membrane fouling [1, 2]. Thus the inoculation and acclimatization of AS is vital to provide more preferably suspended aerobic growth system and desired treatment mechanism for a wastewater which is treated by MBR. There have been some studies on how to acclimatize conventional sludge to synthetic wastewater [1, 3, 4, 5]. Lahiri at al. [6] also reported the acclimatization of seed sludge from a common effluent treatment plant to the synthetic wastewater in order to treat a pharmaceutical industries wastewater. Normally, the acclimatization of AS to synthetic wastewater happens in a sequencing batch reactor (SBR). The reactor is filled with conventional AS and operated under certain hydraulic conditions. A synthetic wastewater together with complemented substrate is then continuously introduced. During this process, it is important to check the $\mathrm{COD} / \mathrm{N} / \mathrm{P}$ ratio, the $\mathrm{pH}$, the temperature and the liquid level in the reactor. When the microbial activity is effective and the constant reduction of soluble COD $(<100$ $\mathrm{mg} / \mathrm{L}$ ) is observed, the process of acclimatization is completed. Sometimes, old membrane module can be added to the reactor to increase the concentration of mixed liquor suspended solids (MLSS).

The bacterial activity during acclimatization can be evaluated by measuring the oxygen needs (by respirometric procedure) and the removal rate of soluble COD. Nowadays, the oxygen demand measurement gains great interest because it is directly linked to the biological activity. Thus, respirometry is considered as an essential parameter for controlling AS process in MBR [7]. It is well known that respirometry has the advantages such as: (i) can be used for those substrates that cannot be easily determined analytically, (ii) much more sensitive than the methods based on biomass growth or substrate removal, (iii) detectable for substrate concentrations below 1 $\mathrm{mg} / \mathrm{L}$, (iv) determines the kinetic constants of mixed cultures without changing the qualitative and quantitative composition of the culture, and (v) simple and easy method [8].

The objective of this study is to investigate oxygen uptake rate (OUR) during the acclimatization of a submerged membrane bioreactor (SMBR) together with a floating media biofilter (FMB). Acclimatized FMB system was connected with crossflow microfiltration (CFMF) system and membrane fouling was investigated under different operation conditions. The acclimatization of a submerged membrane adsorption bioreactor (SMABR) was also studied.

\section{Experimental}

\subsection{Wastewater}

The experiments were conducted using a synthetic wastewater to avoid any fluctuation in the feed concentration and provide a continuous source of completely 
biodegradable organic pollutants. The synthetic wastewater has total organic carbon (TOC) of $120-130 \mathrm{mg} / \mathrm{L}$ and COD of $320-350 \mathrm{mg} / \mathrm{L}$ (COD: $\mathrm{N}: \mathrm{P}=100: 5: 1)$. The composition of synthetic waster is given in Table 1 [1]. $\mathrm{NaHCO}_{3}$ or $\mathrm{H}_{2} \mathrm{SO}_{4}$ were added to the wastewater to maintain a constant $\mathrm{pH}$ around 7 .

Table 1 Constituents of the Synthetic Wastewater

\begin{tabular}{lcc}
\hline Compounds & $\begin{array}{c}\text { Molecular weight } \\
(\mathrm{g} / \mathrm{mol})\end{array}$ & $\begin{array}{c}\text { Concentration } \\
(\mathrm{mg} / \mathrm{L})\end{array}$ \\
\hline Organics and nutrients & & \\
Glucose $\left(\mathrm{C}_{6} \mathrm{H}_{12} \mathrm{O}_{6}\right)$ & 180.0 & 280 \\
Ammonium sulfate $\left(\left(\mathrm{NH}_{4}\right)_{3} \mathrm{SO}_{4}\right)$ & 132.1 & 72 \\
Potassium phosphate $\left(\mathrm{KH}_{2} \mathrm{PO}_{4}\right)$ & 136.1 & 13.2 \\
Trace nutrients & & \\
Calcium chloride $\left(\mathrm{CaCl}_{2} \cdot 2 \mathrm{H}_{2} \mathrm{O}\right)$ & 147.0 & 0.368 \\
Magnesium sulfate $\left(\mathrm{MgSO}_{4} \cdot 7 \mathrm{H}_{2} \mathrm{O}\right)$ & 246.5 & 5.07 \\
Manganese chloride $\left(\mathrm{MnCl}_{2} \cdot 4 \mathrm{H}_{2} \mathrm{O}\right)$ & 197.9 & 0.275 \\
Zinc sulfate $\left(\mathrm{ZnSO} \cdot 7 \mathrm{H}_{2} \mathrm{O}\right)$ & 287.5 & 0.44 \\
Ferric chloride anhydrous $\left(\mathrm{FeCl}_{3}\right)$ & 162.2 & 1.45 \\
Cupric sulfate $\left(\mathrm{CuSO} \cdot 5 \mathrm{H}_{2} \mathrm{O}\right)$ & 249.7 & 0.391 \\
Cobalt chloride $\left(\mathrm{CoCl}_{2} \cdot 6 \mathrm{H}_{2} \mathrm{O}\right)$ & 237.9 & 0.42 \\
Sodium molybdate dihydrate $\left(\mathrm{Na}_{2} \mathrm{MoO}_{4} \cdot 2 \mathrm{H}_{2} \mathrm{O}\right)$ & 242.0 & 1.26 \\
Yeast extract & & 30 \\
\hline
\end{tabular}

\subsection{FMB-SMBR system}

The schematic diagram of acclimatizing the FMB-SMBR system is shown in Figure 1. After acclimatization, FMB works as a pretreatment unit to SMBR system and reduces the fouling of MBR due to its flocculation or filtration functions to avoid severe clogging of the membrane module by small solid particles. The FMB has been successfully applied as a prefilter to crossflow microfiltration in water treatment because of its high solid retention capacity and low headloss development [9]. In this study, the FMB system was operated at filtration rate of $1 \mathrm{~m} / \mathrm{h}$.

Initially, wastewater together with sludge $(3.5 \mathrm{~L})$ from a wastewater treatment plant in Sydney was added in the aeration tank $(10 \mathrm{~L})$ and FMB. Synthetic wastewater was then introduced into the aeration tank gradually up to $10 \mathrm{~L}$ and circulated in FMBSMBR system until it reached acclimatized stage. Polypropylene beads (diameter = $3.8 \mathrm{~mm}$; density $=0.87 \mathrm{~g} / \mathrm{cm}^{3}$ ) is used as floating media on which attached biomass grows. The depth of the floating media was $0.6 \mathrm{~m}$. The suspended biomass in aeration tank and attached biomass in FMB attempt to remove the organic matter in the wastewater and reduce the organic loading on post-treatment procedure. 


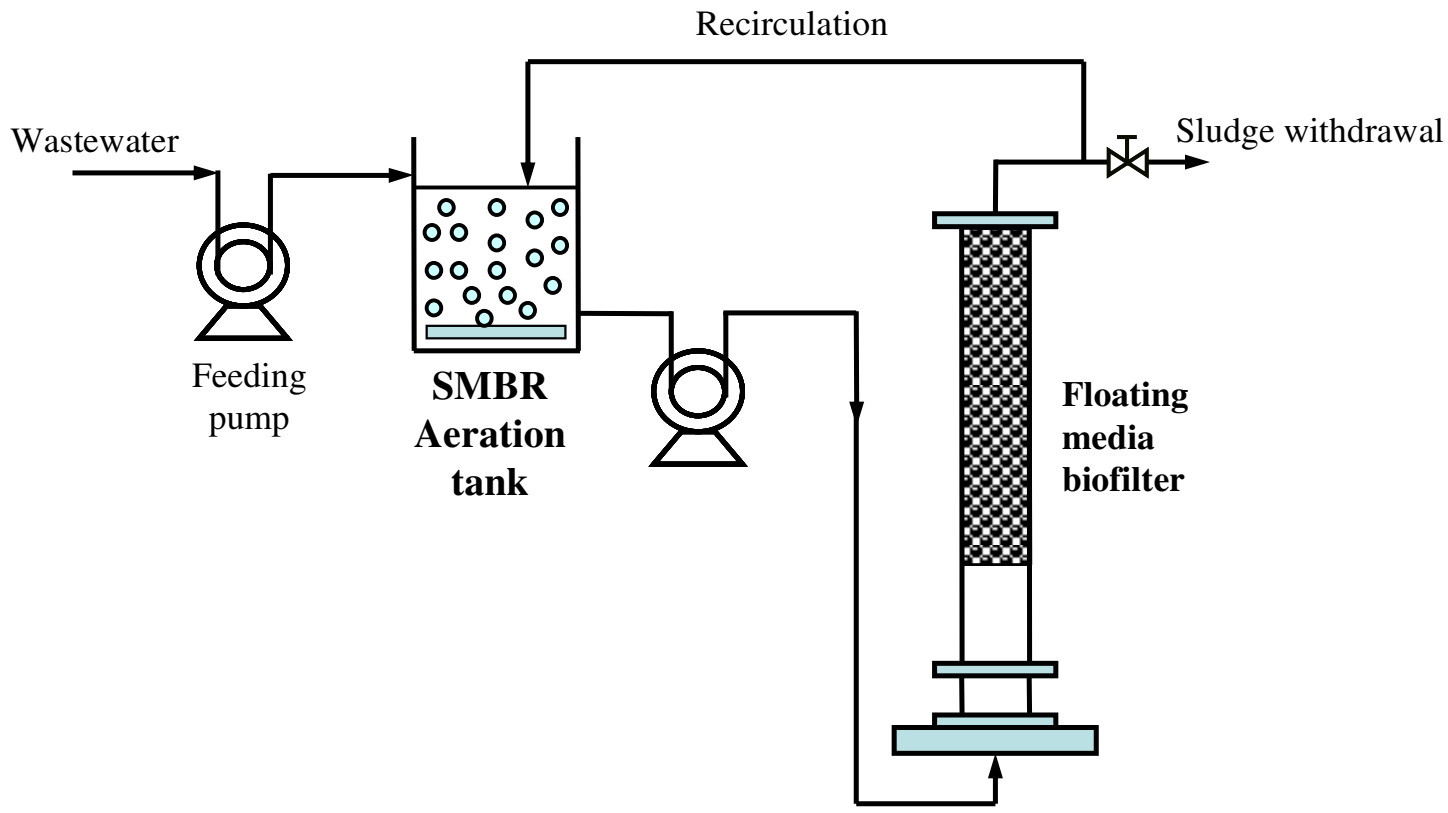

Figure 1 Experimental set-up of acclimatizing FMB-SMBR system

\subsection{SMABR system}

A comparison on acclimatization of FMB-SMBR was made with that of SMABR system. Here SMABR system was acclimatized using synthetic wastewater only. A predetermined amount $(5 \mathrm{~g} / \mathrm{L})$ of powdered activated carbon (PAC) was added into the aeration tank $(10 \mathrm{~L})$ of SMBR with synthetic wastewater at the start of the experiment. The PAC ( $80 \%$ min finer than 75 micron) used was wood based with surface area of $882 \mathrm{~m}^{2} / \mathrm{g}$ and mean pore diameter $30.61 \AA$. There was no further addition PAC during the experimental period. Synthetic wastewater was then added gradually during the acclimatization time to support the microbial growth in the reactor. In such a reactor, bioreaction took place due to the growth of the biomass supported by PAC. The adsorbed organics on the PAC was biodegraded with time by the biomass, and hence it created sites for further adsorption of organics on the PAC.

\subsection{Analysis}

YSI 5300 Biological Oxygen Monitor was used to measure oxygen uptake rate due to its useful tool for measuring samples including respiration, oxidative activity, and cellular metabolism studies. The oxygen consumption measurement can be achieved through use of oxygen electrode with oxygen permeable Teflon membrane. Voltage generated from the reaction is proportional to the oxygen concentration of the sample and produces oxygen uptake or evolution curves in 2 to 15 minutes. During the acclimatization, the wastewater withdrawn from the aeration tank at different periods was monitored. Total organic carbon (TOC) of the influent and effluent was measured using the Analytikjena Multi N/C 2000. For measuring MLSS, three samples were taken each time and the average values were than calculated. 


\section{Results and Discussion}

\subsection{Acclimatization of FMB-SMBR system and SMABR system}

The duration of sludge from wastewater treatment plant in Sydney acclimated to synthetic wastewater was about 25 days for FMB-SMBR system, while SMABR took around 12 days to reach the stabilization. The average concentrations of MLSS and TOC removal efficiency in two systems are shown in Figures 2 and 3. As can be seen from these figures, the MLSS (approximately $6.2 \mathrm{~g} / \mathrm{L}$ ) and TOC removal efficiency (approximately 94\% removal) were steady after 25 days' acclimatization of FMBSMBR system. The average concentrations of MLSS and TOC removal efficiency kept constant even after 60 days, which were 6.47 and $95.1 \%$ respectively. The growth of the biomass was steady and gradual. However, steep slopes were observed in both biomass growth and TOC removal of SMABR system. The low TOC removal indicated that adsorption could not remove organic substances present in synthetic wastewater. The better TOC removal efficiency $(70 \%)$ was achieved only when the biodegradation predominated over adsorption. The acclimatized FMBR-SMBR system showed more than $20 \%$ TOC removal efficiency than that of the acclimatized SMABR system.

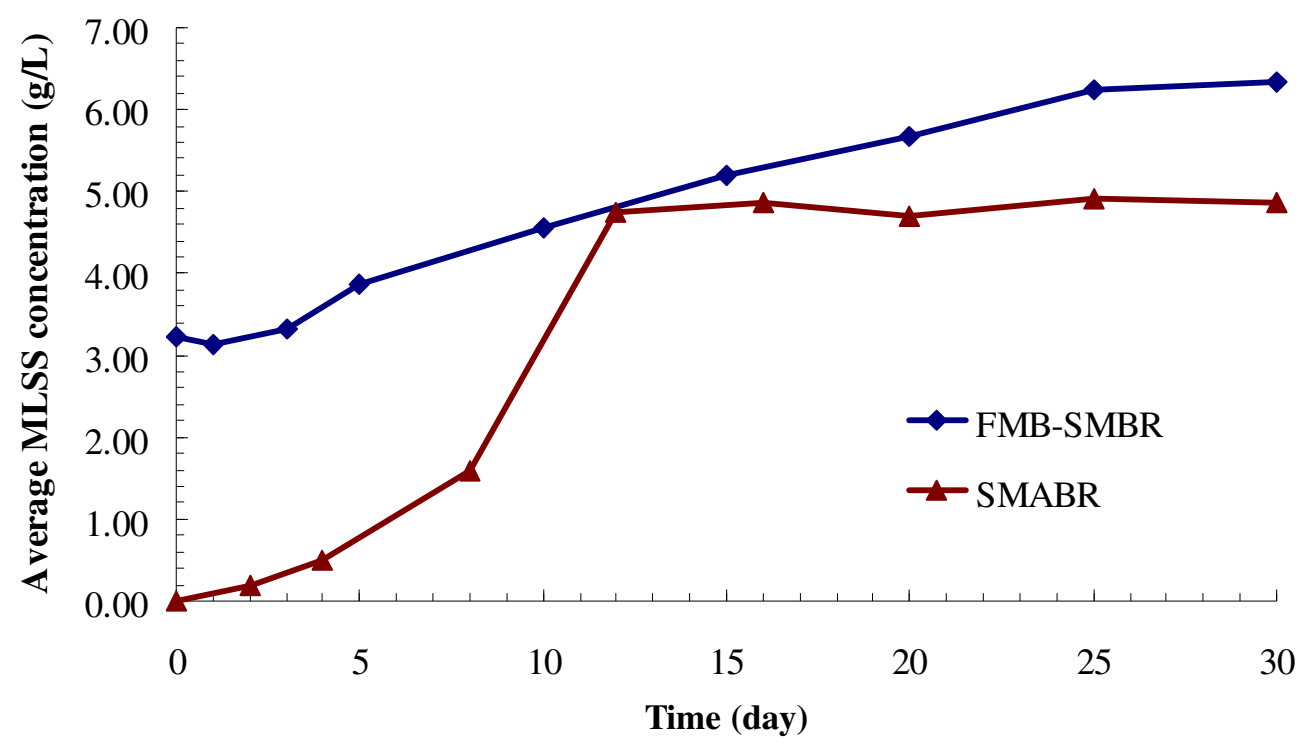

Figure 2 The average MLSS concentration in FMB-SMBR and SMABR systems 


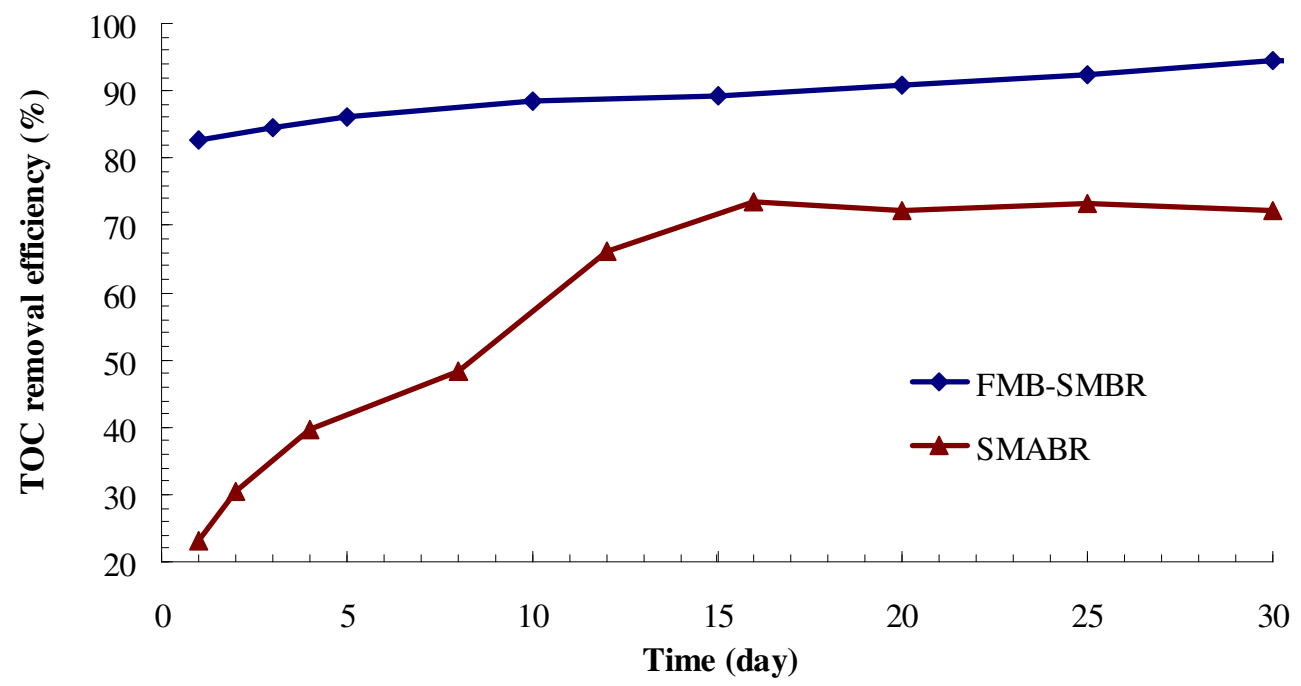

Figure 3 The TOC removal efficiency in FMB-SMBR and SMABR systems

OUR was used to indicate the dissolved oxygen (DO) consumption rates in both FMB-SMBR and SMABR systems. The OURs during acclimatization of the two systems are presented in Figures 4 and 5. The results showed that the higher the OUR, the more efficient of bacterial biodegradation could be achieved. Before the acclimatization of both systems, the OURs were quite low (45\% for FMB-SMBR system and $20 \%$ for SMABR system). After the acclimatization, the OUR in FMBSMBR system was around $65 \%$. On the other hand, the OUR in SMABR system was only $37 \%$, which means there were more microbial substances in FMB-SMBR system and the same conclusions were drawn from MLSS and TOC removal efficiency. Therefore, OUR can be a simple accurate way to indicate the acclimatization of biological processes.

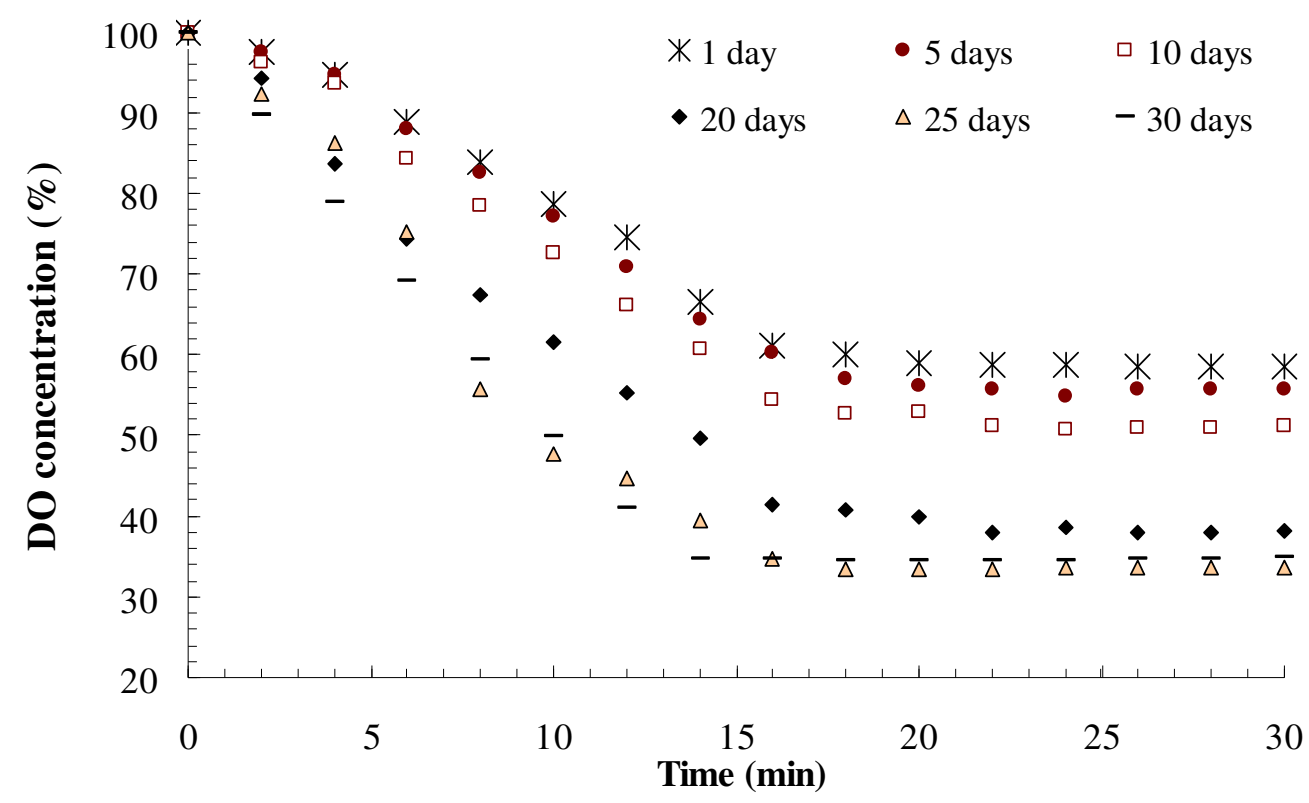

Figure 4 OUR variation of the wastewater in FMB-SMBR system 


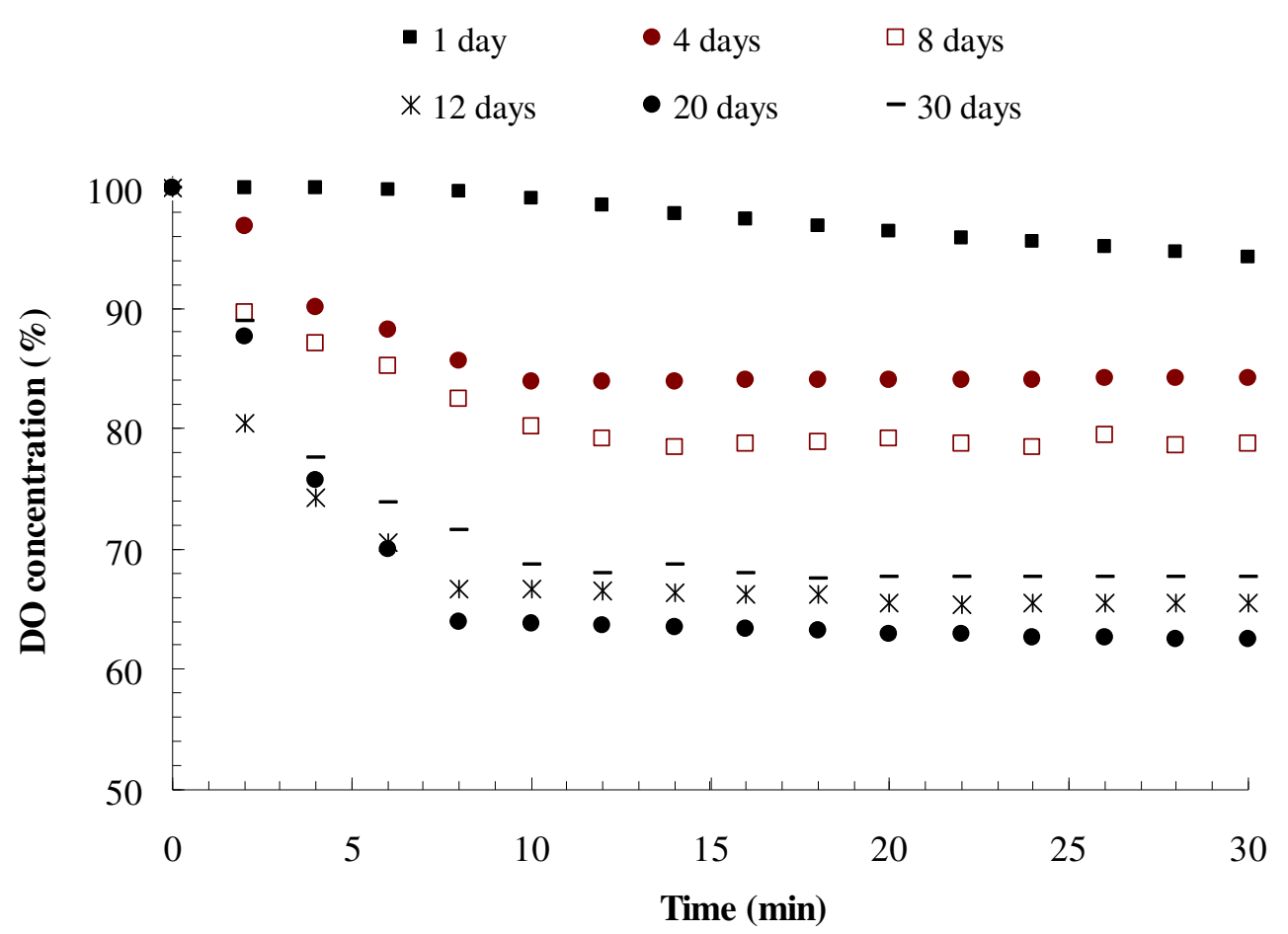

Figure 5 OUR variation of the wastewater in SMABR system

\subsection{Settleable solids test}

The settleability of suspended solid in FMB-SMBR system was also studied. As can be seen from Table 2, the flocs could settle down quickly without any adjustment of $\mathrm{pH}$ value. The settleability of flocs was quite high and the solids observed were dense and easy to be settled.

Table 2 Results of settable solids experiments

\begin{tabular}{cc}
\hline Item & Wastewater \\
\hline $\begin{array}{c}\text { The first settleable solids reaching } \\
\text { the bottom of the cone }\end{array}$ & $27 \mathrm{sec}$ \\
$\begin{array}{c}\text { The settleable solids volume } \\
\text { after } 1 \text { hour }(\mathrm{ml} / \mathrm{L})\end{array}$ & 90 \\
\hline
\end{tabular}

\subsection{Membrane fouling study of FMB-CFMF system}

The acclimatized FMB was connected with crossflow microfiltration (CFMF) and membrane fouling was investigated under different operation conditions. The effluent from FMB system was collected in a bucket before applied to CFMF. The PVDF (modified polyvinylidene difluoride) Minitan-S Microporous membranes (with pore size of $0.45 \mu \mathrm{m}$ ) were used. The total membrane area was $3.24 \times 10^{-3} \mathrm{~m}^{2}$. The FMB system was operated at filtration rate of $1 \mathrm{~m} / \mathrm{h}$. Experiments were carried out at 
different cross flow velocity to study its effect on development of transmembrane pressure (TMP) (Figure 6). The Reynolds number and shear stress calculated for different crossflow velocity together with the TMP increases are listed in Table 3.

Table 5.4 The Reynolds number (Re) and shear stress values for different crossflow velocities

\begin{tabular}{ccccc}
\hline $\begin{array}{c}\text { Crossflow } \\
\text { velocity }(\mathrm{m} / \mathrm{s})\end{array}$ & $\begin{array}{c}\text { Flow rate } \\
\left(\mathrm{L} / \mathrm{m}^{2} . \mathrm{h}\right)\end{array}$ & Reynolds number & $\begin{array}{c}\text { Shear stress } \\
(\mathrm{pa})\end{array}$ & $\begin{array}{c}\text { TMP increase } \\
(\mathrm{kPa})\end{array}$ \\
0.15 & 3240 & 120 & 2.97 & 36.0 \\
0.30 & 6481 & 240 & 5.94 & 22.6 \\
0.45 & 9722 & 360 & 8.91 & 17.4 \\
0.60 & 12962 & 480 & 11.88 & 17.3 \\
\hline
\end{tabular}

As can be seen in Figure 6, when crossflow velocity was $0.15 \mathrm{~m} / \mathrm{s}$, the TMP reached to the highest value of $36 \mathrm{kPa}$ after 5-hour filter run. With higher crossflow velocities, the increases of TMP were low. However, the increase of TMP value did not improve when the crossflow velocity was operated from $0.45 \mathrm{~m} / \mathrm{s}$ to further value of $0.60 \mathrm{~m} / \mathrm{s}$. This means the crossflow velocities of $0.30 \mathrm{~m} / \mathrm{s}$ or $0.45 \mathrm{~m} / \mathrm{s}$ were efficient to prevent physical fouling of the membrane. The membrane fouling was found due to the biofouling of the biomass present in effluent supernatant.

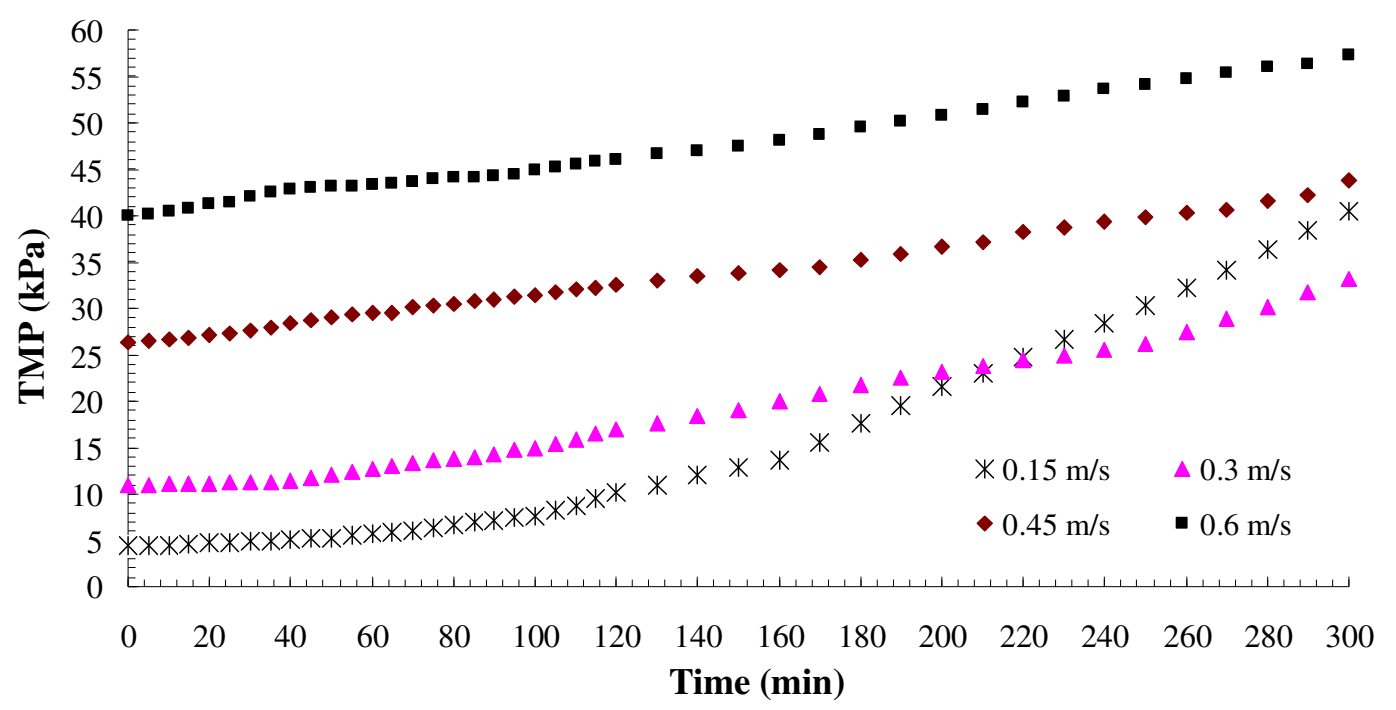

Figure 6 Effect of crossflow velocity on TMP increase of FMB effluent (membrane pore size $=0.45 \mu \mathrm{m}$; filtration flux $=100 \mathrm{~L} / \mathrm{m}^{2} . \mathrm{h}$ )

The effect of filtration flux on TMP increase was studied by varying the filtration flux in the range of $100-200 \mathrm{~L} / \mathrm{m}^{2} . \mathrm{h}$ (Figure 7). As expected, the lower filtration flux led to the lowest TMP development $(22.1 \mathrm{kPa})$ over the filtration time of 300 minutes. During first hour of operation, the TMP development was inconspicuous at filtration flux of $100 \mathrm{~L} / \mathrm{m}^{2}$.h suggesting that if periodic backwash frequency is adopted within 
one hour, the membrane reversible fouling can be restored. The average TOC removal efficiencies were $95.4 \%, 94.6 \%$ and $93.2 \%$ at the filtration fluxes of $100 \mathrm{~L} / \mathrm{m}^{2} . \mathrm{h}, 150$ $\mathrm{L} / \mathrm{m}^{2} . \mathrm{L}$ and $200 \mathrm{~L} / \mathrm{m}^{2} . \mathrm{h}$ respectively over the filtration time of 300 minutes. In practice, the range of permeate flux for SMBR is 5 to $20 \mathrm{~L} / \mathrm{m}^{2} . \mathrm{h}$. Thus, the acclimatized FMB-SMBR system can be operated under sub-critical flux condition without significant fouling. FMB can be used as a pretreatment unit prior to SMBR, since it can reduce the loading of organic substances to membrane in MBR and minimize membrane fouling.

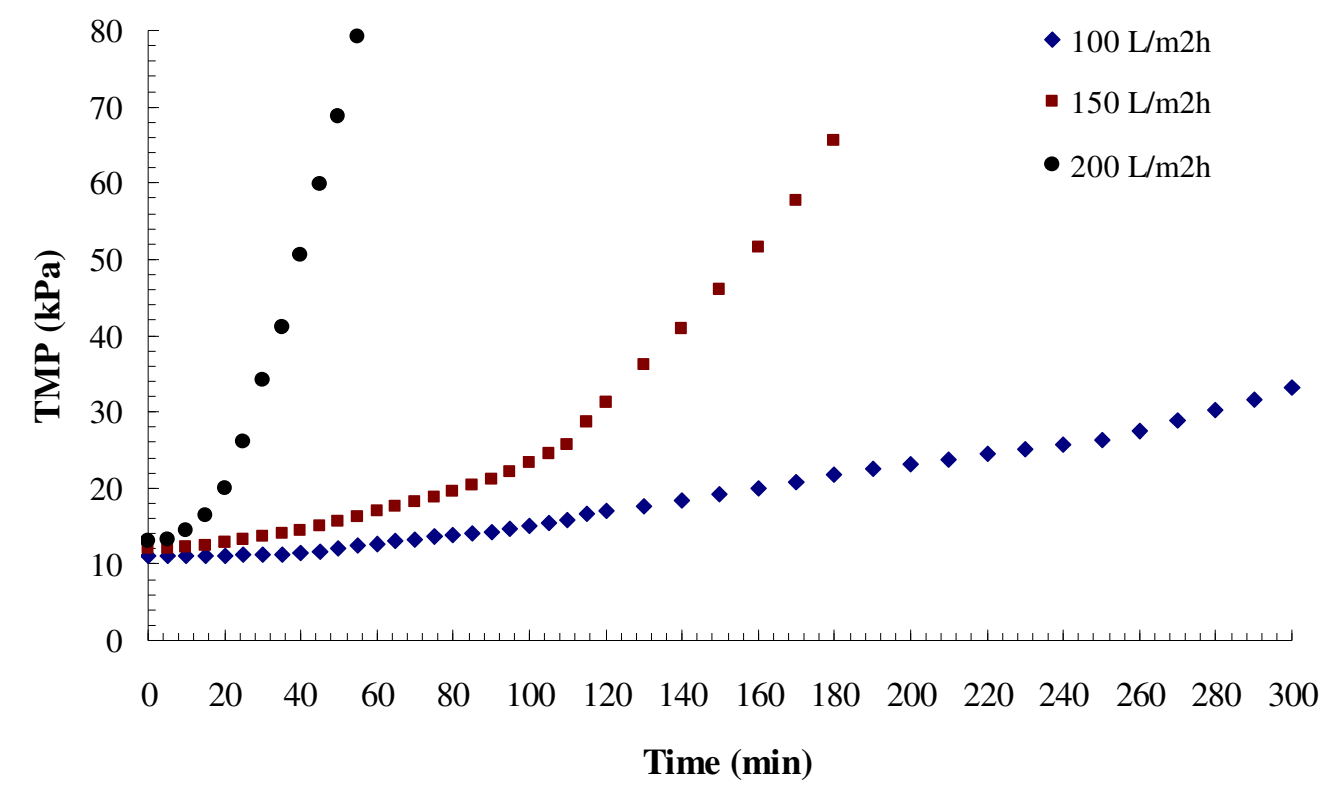

Figure 7 Effect of filtration flux on TMP increase of FMB effluent (membrane pore size $=0.45 \mu \mathrm{m}$; crossflow velocity $=0.30 \mathrm{~m} / \mathrm{s}$ )

\section{Conclusions}

It took about 25 days for an activated sludge from a wastewater treatment plant in Sydney to get acclimated to synthetic wastewater in FMB-SMBR system, while SMABR spent around 12 days to reach the stabilization. The acclimatized FMBSMBR (without membrane operation) was very effective in removing dissolved organic substances (94\% removal efficiency) from the synthetic wastewater and FMB can be used as a pretreatment process prior to SMBR in order to reduce membrane fouling.

It was proved that the OUR is an accurate and simple indicator to biological process acclimatization. After the acclimatization, the OUR in FMB-SMBR system was around $65 \%$, while the OUR in SMABR system was only 37\%. The OURs were corresponding to the MLSS and TOC removal efficiency results of mixed liquor in both acclimatized systems.

Connecting acclimatized FMB with CFMF shows the high TOC removal efficiency (over 90\%) and the TMP development was only $22.1 \mathrm{kPa}$ when FMB-CFMF was operated at filtration flux of $100 \mathrm{~L} / \mathrm{m}^{2}$.h. The acclimatized FMB can be used as a 
pretreatment unit prior to SMBR. It reduced the loading of organic substances to membrane in MBR and minimized membrane fouling when the FMB-SMBR system operates under sub-critical flux condition (filtration flux $<100 \mathrm{~L} / \mathrm{m}^{2} . h$; backwash frequency $<1$ hour). Further study on the FMB-SMBR system is thus necessary.

\section{Acknowledgment}

This research was funded by DEST International Science Linkages Competitive Grant.

\section{References}

[1] W. Lee, S. Kang, and H. Shin, Sludge characteristics and their contribution to microfiltration in submerged membrane bioreactors, Journal of Membrane Science, 216 (2003) 217-227.

[2] P. L Clech, B. Jefferson, I. S. Chang and S. J. Judd, Critical flux determination by the flux-step method in a submerged membrane bioreactor, Journal of Membrane Science, 227 (2003) 81-93.

[3] H. Y. Ng and S. W. Hermanowicz, Membrane bioreactor operation at short solids retention times: performance and biomass characteristics, Water Research, 39 (2005) 981-992.

[4] N. Ren, Z. Chen, S. A. Wang and D. Hu, Removal of organic pollutants and analysis of MLSS-COD removal relationship at different HRTs in a submerged membrane bioreactor, International Biodeterioration \& Biodegradation 55 (2005) 279-284.

[5] M. E. Hernandez Rojas, R. Van Kaam, S. Schetrite and C. Albasi, Role and variations of supernatant compounds in submerged membrane bioreactor fouling, Desalination, 179 (2005) 95-107.

[6] S. Lahiri, S. T. Khan, D. Mukkanti, V. R. Akella and Y. Anjaneyulu, Aerobic stabilisation of pharmaceutical wastewaters using large scale extended aeration activated sludge process, http://www. geocities.com/saugath/1.htm?200514.

[7] M-L. Rodde-Pellegrin, C. Wisniewski, A. Grasmick, A. Tazi-pain and H. Buisson, Respirometric needs of heterotrophic populations developed in an immersed membrane bioreactor working in sequenced aeration. Biochemical Engineering, 11 (2002) 2-12.

[8] P. Pitter and J. Chudoba, Biodegradability of organic substances in the aquatic environment, CRC Press, Boca Raton, 1990.

[9] C. Chiemchaisri, W. Chiemchaisri, T. Kornboonraksa, C. Dumrongsukit, S. Threedeach, H. H. Ngo and S. Vigneswaran, Particle and microorganism removal in floating plastic media coupled with microfiltration membrane for surface water treatment, Desalination, 106(1-3) (1996) 39-45. 